\title{
Fernando Pessoa e o gênio romântico
}

Cláudia Souza - USP-FAPESP

\author{
Minha alma é uma orchestra \\ oculta; \\ não sei que instrumentos \\ tangem e rangem cordas, \\ harpas, timbales e tambores, \\ dentro de mim. \\ Só me conheço como \\ symphonia.
}

Fernando Pessoa [BNP/E3-4-68]

Fernando Pessoa foi um leitor ávido. Os registros deixados em sua biblioteca particular nos permitem comprovar o seu interesse pelo primeiro romantismo alemão. Em sua biblioteca particular constam: um livro de Novalis Les disciples à Sais et Les fragments ${ }^{1}$ curiosamente traduzido por Maeterlink ${ }^{2}$, um

${ }^{1}$ Novalis, Friedrich von Hardenberg. Les disciples à Sais et Les fragments. Traduits de l'allemand et précédés d'une introduction par Maurice Maeterlinck. Paris-Bruxelles: Paul Lacomblez 1914.

${ }^{2}$ Pessoa foi muito influenciado pelo teatro simbolista de Maeterlink. Em seus projetos do Teatro estático encontramos referências ao dramaturgo belga (Cf: Pessoa, 2010). 
livro sobre o romântico alemão, intitulado Novalis $^{3}$ e um exemplar do livro The literature of Germany ${ }^{4}$ onde existe um capítulo sobre o romantismo alemão. A presença destes dois livros no espólio revela o interesse pessoano pelo romantismo alemão. Para além destes indícios, encontramos referência a Friedrich Schlegel e a Novalis em documentos pessoanos ${ }^{5}$.

Um primeiro ponto de aproximação entre Pessoa e o gênio romântico ocorre através da simetria entre a questão do gênio - para F. Schlegel e Novalis - e a presença de uma coletividade interior. No capítulo IX do livro O Gênio Romântico, intitulado Mitologia e História da Filosofia, Márcio Suzuki analisa essa proximidade:

O gênio, diz Schlegel, é uma coletividade interior, uma 'comunidade interna legalmente livre de muitos talentos', ou como diz Novalis, 'uma pessoa genuinamente sintética', 'uma pessoa que é ao mesmo tempo mais pessoas. (Suzuki, 1998, p. 235).

"Uma pessoa que é ao mesmo tempo mais pessoas", remete justamente ao espaço literário pessoano, onde muitos eus existem, coexistem, criam poesias - como é o caso dos heterônimos, Alberto Caeiro, Álvaro de Campos e Ricardo Reis - assinam projetos em prosa - como é o caso de Bernardo Soares que assina

${ }^{3}$ Lichtenberger, Henri. Novalis. 2ed. Paris: Bloud \& Cie, 1912.

${ }^{4}$ Robertson, J. G. The literature of Germany. London: Williams and Norgate - New York : Henry Holt and Company, [s/d]

5 No artigo, "Novalis e Pessoa: lucidez poética e reflexão onírica" (Souza; Suzuki, 2015), mostramos a proximidade entre Pessoa e Novalis através de documentos do espólio pessoano e uma análise reflexiva. 
o projeto do Livro do Desassossego. A análise deste primeiro ponto sobre o gênio romântico possibilita a aproximação entre a noção gênio romântico e a criação literária pessoana.

No trecho citado está evidente a importância do processo reflexivo: se o gênio é uma coletividade interior ou uma pessoa sintética, esse desdobramento interior ocorre através da reflexão. Existe, no que toca a questão do gênio, uma certa consonância entre o pensamento de F. Schlegel e de Novalis. Ambos relacionam gênio e multiplicidade interior, como se pode atestar na passagem citada. E a coletividade interior só pode ser fruto de um movimento reflexivo, onde o sujeito cria espaços interiores fragmentando assim a sua suposta unidade.

Em um documento do espólio pessoano que pertence a um projeto intitulado Aspectos, que seria composto por um conjunto de livros de autoria de eus pessoanos, Pessoa discorre sobre a sua multiplicidade interior:

O author humano d'estes livros não conhece em siproprio personalidade nenhuma. Quando acaso sente uma personalidade emergir dentro de si, cedo vê que é um ente differente do que elle é, embora parecido; filho mental, talvez, e com qualidades herdadas, mas as differenças de ser outrem.

Que esta qualidade no escriptor seja uma forma da hysteria, ou da chamada dissociação da personalidade, o author d'estes livros nem o contesta, nem o appoia. De nada lhe serviriam, escravo como é da multiplicidade de si- proprio, que concordasse com esta, ou com aquella, theoria, sobre os resultados escriptos d'essa multiplicidade. 
Que este processo de fazer arte cause extranheza, não admira; o que admira é que haja cousa alguma que não cause extranheza ${ }^{6}$

Essa passagem revela a consciência pessoana em relação à sua multiplicidade, à sua coletividade interior. A intensidade do seu processo reflexivo o faz perceber a falta de uma personalidade e a presença de uma coletividade interior, pois quando acaso sente uma personalidade emergir dentro de si, cedo vê, que é um ente diferente do que ele é, embora parecido. É interessante perceber o papel da reflexão na composição dramática da literatura pessoana. Pessoa ao identificar uma personalidade, percebe uma distância entre ele e essa personalidade, um estranhamento, que acontece a partir de uma dobra que se instaura no sujeito, num espaço que existe entre o eu e o mundo, no caso desta passagem, entre o eu e o outro que se assemelha a Pessoa, mas que é outra pessoa. E é através deste distanciamento criado através do movimento reflexivo, que outros eus vão emergindo na interioridade pessoana, uma multiplicidade de si próprio, como diz Pessoa, ou uma coletividade interior, como dizem os primeiros românticos alemães. Há uma simetria, uma consonância entre a questão do gênio romântico e a criação literária pessoana.

Realizada essa primeira aproximação entre o gênio romântico e Pessoa, é preciso aprofundar o significado da noção de gênio para os primeiros românticos alemães. No pensamento de F. Schlegel e Novalis há uma diferença entre gênio e gênio do gênio, como se pode atestar na seguinte passagem escrita por Novalis:

Quem procura, duvidará. O gênio porém diz tão atre-

${ }^{6}$ Optamos aqui e nas demais transcrições dos documentos pessoanos ao longo do artigo por manter a ortografia original. [BNP/E3-20-70] 
vida e seguramente o que vê passar-se dentro de si porque não está embaraçado em sua exposição e, portanto, tampouco a exposição embaraçada nele, mas sua consideração e o considerado parecem consoar livremente, unificar-se livremente numa obra única. Quando falamos do mundo exterior, quando descrevemos objetos efetivos, então procedemos como gênio. Sem genialidade nós simplesmente não existiríamos. Gênio é necessário para tudo. Aquilo, porém, que de costume se denomina gênio, é o gênio do gênio ${ }^{7}$. (Schlegel, 1997, pp. 97-98).

Neste fragmento encontramos a defesa da presença da genialidade em todos nós, pois ao falar do mundo exterior, ao descrever objetos agimos como gênios. Num outro fragmento, F. Schlegel parece estar de acordo com Novalis: "Todo homem completo tem um gênio. A verdadeira virtude é a genialidade." (Ibid., p. 148) Gênio e genialidade seriam assim atributos dos seres humanos. De acordo com Novalis: sem genialidade não existiríamos. Porém, como pode ser constatado no final do fragmento de Novalis há uma diferença entre gênio e gênio do gênio. O que se chama de gênio habitualmente, ou seja, aquele indivíduo que é um sistema de talentos, especial, capaz de criações exemplares, seria o gênio do gênio. Neste ponto percebemos mais uma vez o importante papel da reflexão no pensamento do primeiro romantismo alemão ${ }^{8}$. Para ser gênio do gênio é preciso se desdobrar

\footnotetext{
7 Grifo nosso.

${ }^{8}$ No livro O Gênio Romântico, Márcio Suzuki, discute essa questão do gênio do gênio, no Capítulo III (A arte de filosofar), revelando a influência do pensamento de Kant e Fichte para o romantismo e lançando luz sobre a proposta da sinfilosofia.
} 
dentro da sua própria interioridade. É importante ressaltar que Pessoa realizou justamente essa premissa, se desdobrou inúmeras vezes dentro de si mesmo e para cada desdobramento criou um outro eu, uma outra personalidade. Em seu espólio encontramos inúmeras assinaturas, responsáveis por muitos projetos, grande parte incompletos. A marca da sua suposta completude talvez só possa ser analisada através desta incompletude: Pessoa parece ter sido gênio do gênio durante toda a sua existência e as consequências desta reflexão levadas ao máximo podem ser percebidas no seu espaço literário. No trecho de uma carta datada de 13 de Janeiro de 1935, Pessoa confessa que desde criança tinha a tendência ao desdobramento:

Desde criança tive a tendência para criar em meu torno um mundo fictício, de me cercar de amigos e conhecidos que nunca existiram. (Não sei, bem entendido, se realmente não existiram, ou se sou eu que não existo. Nestas coisas, como em todas, não devemos ser dogmáticos). Desde que me conheço como sendo aquilo a que chamo eu, me lembro de precisar mentalmente, em figura, movimentos, carácter e história, várias figuras irreais que eram para mim tão visíveis e minhas como as coisas daquilo a que chamamos, porventura abusivamente, a vida real. Esta tendência, que me vem desde que me lembro de ser um eu, tem-me acompanhado sempre, mudando um pouco o tipo de música com que me encanta, mas não alterando nunca a sua maneira de encantar. (Pessoa, 1999b, p. 341).

Esse texto mostra a capacidade do artista em analisar a prin- 
cipal característica da sua obra: a multiplicidade. Esse é um traço que acompanha não somente a personalidade pessoana (que se desdobra em tantas outras personalidades), mas do seu espaço literário. São inúmeros projetos, que se multiplicam de forma extraordinária dentro do seu espólio, colocando o pesquisador diante de mosaicos que podem ser colados de diversas formas. Para além disto, chama a atenção no texto, a ironia pessoana ao duvidar da sua própria existência, outro traço que aproxima Pessoa do primeiro romantismo: Não sei, bem entendido, se realmente não existiram, ou se sou eu que não existo. Nestas coisas, como em todas, não devemos ser dogmáticos. Deixaremos, no entanto, essa questão para ser explorada em outro artigo e voltemos à relação entre gênio romântico e literatura pessoana.

É interessante perceber que não é somente Pessoa que analisa a sua multiplicidade e o seu desencontro consigo próprio. Outros eus também escrevem sobre essa multiplicidade interior, como é o caso de Ricardo Reis:

Vivem em nós inúmeros;

Se penso ou sinto, ignoro

Quem é que pensa ou sente.

Sou somente o lugar

Onde se sente ou pensa.

Tenho mais almas que uma.

Há mais eus do que eu mesmo.

Existo todavia

Indiferente a todos.

Faço-os calar: eu falo.

Os impulsos cruzados 
Do que sinto ou não sinto

Disputam em quem sou.

Ignoro-os. Nada ditam

A quem me sei: eu escrevo.

(Reis, 2000, pp. 137-138)

No poema, o eu lírico assume a sua multiplicidade e a disputa interior entre os impulsos e sentimentos. Reis reconhece ser palco de uma coletividade (Vivem em nós inúmeros), mas afirma que através da palavra consegue ignorar essa multiplicidade e se fazer: Os impulsos cruzados/Do que sinto ou não sinto/Disputam em quem sou./Ignoro-os. Nada ditam/A quem me sei: eu escrevo. Para Reis é a palavra escrita que consegue transformar tantos eus em um só, aquele que assina o poema. A unidade da assinatura parece esconder esse palco, onde outras almas, outras vozes se cruzam. Reis não é Pessoa, é um outro, fruto de um desdobramento, criado a partir de uma dobra entre o eu e a realidade, uma dobra que comporta Reis e toda a sua coletividade interior, fictícia, já não é mais o gênio que diz algo, mais o gênio do gênio, no caso o Reis de Pessoa.

Álvaro de Campos parece também estar de acordo com esse desacordo que Pessoa e Reis sentem em relação à unidade. Num poema, Campos, que é tão diferente de Pessoa e de Reis, com uma biografia própria, estilo próprio, e até mesmo tendo discutido publicamente (em revistas) com seu criador ${ }^{9}$, demonstra que também tinha o seu eu permeado por inúmeras dobras:

${ }^{9} \mathrm{Na}$ revista Contemporânea, n ${ }^{\circ}$ 4, publicada 04 de Outubro em 1922, Álvaro de Campos publica um texto discordando da interpretação pessoana do livro Canções de António Botto. Pessoa havia publicado um artigo sobre Canções na mesma revista que Campos, no número anterior (Contemporânea, $\mathrm{n}^{\circ}$ 3, 03 de Julho de 1922). O conteúdo do texto de Campos é muito interessante e altamente irônico, como podemos constatar na seguinte 
Mas eu, em cuja alma se reflectem

As forças todas do universo,

Eu cuja reflexão emotiva e sacudida

Minuto a minuto, emoção a emoção,

Coisas antagónicas e absurdas se sucedem -

Eu o foco inútil de todas as realidades,

Eu o fantasma nascido de todas as sensações,

$\mathrm{Eu}$ o abstracto, eu o projectado no écran,

Eu a mulher legítima e triste do Conjunto,

Eu sofro ser eu através disto tudo como ter sede sem ser de água.

(Pessoa, 2007a, p. 249).

Novamente aparece a palavra alma, e uma relação entre o eu e a reflexão, como no poema de Reis (Tenho mais almas que uma/Há mais eus do que eu mesmo). É interessante perceber que quem assina este poema é Álvaro de Campos, que como se sabe é fruto da reflexão/desdobramento de Pessoa, e esse outro eu pessoano confessa em sua poesia ter o seu eu atravessado por inúmeras sensações, forças do universo, é um eu tão multifacetado quanto o eu do seu próprio criador. Uma suposta identidade que mostra um processo de reflexão infinito, num movimento que percorre toda a obra pessoana, um espaço inquieto em permanente mudança. Não seria essa a característica do gênio do gênio: a capacidade infinita de reflexão, revelando ao leitor uma coletividade interior?

passagem: "Continua o Fernando Pessoa com aquela mania, que tantas vezes lhe censurei, de julgar que as coisas se provam. Nada se prova senão para ter a hipocrisia de não afirmar. O raciocínio é uma timidez duas timidezes talvez, sendo a segunda a de ter vergonha de estar calado." (PESSOA, 1999a, pp. 186-189). 
Entre Pessoa, seu espaço literário e a noção de gênio romântico já encontramos dois pontos de contato: primeiro é relativo à coletividade interior e o segundo à questão do processo reflexivo que torna Pessoa gênio do gênio. As duas questões estão relacionadas, pois é através da coletividade interior (característica do gênio romântico) que Pessoa desenvolve o gênio do gênio, ou seja, os outros eus que são capazes de dobrar-se sobre eles mesmos, como percebemos nos poemas assinados por Reis e Campos. Essa questão do gênio do gênio nos remete a outros dois aspectos da primeira filosofia romântica alemã, a questão da sinfilosofia e da simpoesia. O filosofar em conjunto e o poetar em conjunto eram propósitos muito importantes para Friedrich Schlegel e Novalis. No fragmento 125 do Athenäum lemos a esse respeito:

Uma época inteiramente nova das ciências e arte começaria talvez quando a sinfilosofia e a simpoesia tivessem se tornado tão universais e tão interiores, que já não seria nada raro se algumas naturezas que se complementam reciprocamente constituíssem obras em conjunto. Muitas vezes não se pode evitar o pensamento de que dois espíritos poderiam no fundo pertencer um ao outro, como metades separadas, e só juntos ser tudo o que pudessem ser. Se houvesse uma arte de fundir indivíduos, ou se a crítica desejosa conseguisse algo mais que desejar, para isso encontrado em toda parte muita ocasião, então eu gostaria de ver combinados Jean Paul e Peter Leberecht. Tudo aquilo que falta a um, o outro possui: juntos, o talento grotesco de Jean Paul e a formação fantástica de Peter Leberecht produziram um notável poeta romântico. (Schlegel, 1997, 
pp. 67-68).

Tanto F. Schlegel quanto Novalis defendiam esse elaboração de obras em conjunto. Pois as naturezas artísticas poderiam se complementar, constituindo obras muito mais ricas e interessantes do que as mesmas seriam se realizadas por um só indivíduo. A proposta de uma arte de fundir indivíduos parece ter sido realizada por Pessoa. No seu movimento reflexivo interior, que nos leva a aproximá-lo do gênio do gênio, Pessoa criou uma literatura composta por muitos indivíduos que se completam. Um exemplo da simpoesia e sinfilosofia pessoana é o seu drama em gente, diálogo existente entre os seus eus. Num outro fragmento do texto que pertence ao projeto Aspectos, Pessoa defende a criação dos seus companheiros de espírito, justamente porque ele é um homem de gênio:

Com uma tal falta de litteratura, como ha hoje, que pode um homem de genio fazer senão converter-se, elle só, em uma litteratura? Com uma tal falta de gente coexistivel, como ha hoje, que pode um homem de sensibilidade fazer senão inventar os seus amigos, ou, quando menos, os seus companheiros de espirito? [BNP/E3-20-72]

Essa passagem nos revela um Pessoa consciente de seu potencial artístico (um homem de gênio) que disposto a superar uma época literária pouco fértil, converteu-se ele só em uma literatura e como homem de sensibilidade criou seus amigos, seus companheiros de espírito. Neste caso Pessoa está se referindo a Alberto Caeiro, Álvaro de Campos, Ricardo Reis, António Mora e Vicente Guedes, como podemos confirmar na seguinte lista: 
"ASPECTOS".

Prefacio geral

1. Alberto Caeiro (1889 - 1915) - "O Guardador de Rebanhos" e outros poemas e fragmentos

black 2. Ricardo Reis: "Odes".

3. Antonio Mora: "Alberto Caeiro e a Renovação do paganismo".

4. Alvaro de Campos: "Arco de Triunpho" Poemas.

5. Vicente Guedes: "Livro do Desasocego".

[BNP/E3-48C-29]

Os companheiros de espírito pessoanos, os gênios dos gênios têm uma obra em conjunto, o projeto Aspectos é a comprovação deste fato. Se as obras encontram-se unidas em um projeto pessoano é porque há um diálogo entre elas. É interessante perceber nesta lista o papel de António Mora, que seria o continuar filosófico de Alberto Caeiro. A obra Alberto Caeiro e a renovação do paganismo servem justamente como exemplo de sinfilosofia, pois a escrita de Mora ocorre a partir da poesia pagã do mestre Caeiro. A relação entre Pessoa e a sinfilosofia e simpoesia se estende para além do projeto Aspectos. Na poesia e na prosa tanto de Campos e de Reis, a influência do Mestre Caeiro também aparece. Como podemos averiguar no seguinte poema assinado por Álvaro de Campos:

Ah, estou liberto!

Ah, quebrei todas 
As algemas do pensamento.

Eu, o claustro e a cave voluntários de mim mesmo, Eu o próprio abismo que sonhei, $\mathrm{Eu}$, que vi em tudo caminhos e atalhos de sombra E a sombra e os caminhos e os atalhos eram eu! Ah, estou liberto...

Mestre Caeiro, voltei à tua casa do monte E vi o mesmo que vias, mas com meus olhos, Verdadeiramente com meus olhos, Verdadeiramente verdadeiros...

Ah vi que não há muitos abismos!

Vi que $\square$ [BNP/E3-64-33 v].

E num texto do Ricardo Reis lemos também:

Quando pela primeira vez, estando então em Portugal, ouvi lerO Guardador de Rebanhostextittive a maior e a mais perfeita sensação da minha vida. Rolou-se-me de sobre o coração, de repente, todo o peso da nossa civilização portuguesa, todo o peso do cristianismo avito cuja sombra jaz sobre a nossa alma. Respirei outra vez a grandeza, a força e a singela perfeição das grandes emoções primitivas, provindas da natureza sem data das almas. Abriram-se-me de par em par, visualmente, as portas com que Amon começa o dia. Senti-me diferente, como um mortal chamado ao convívio dos Deuses. E na verdade dos Deuses, que não de Caeiro, era 
aquela obra espantosa. Nunca poderei esquecer essas horas de surpreendente convívio em que vi, em toda a sua frescura e certeza, a Natureza natural frente a frente. [BNP/E3-52A-10].

No poema de Campos temos um exemplo da simpoesia romântica. O autor do poema é Campos, gênio do gênio, ou seja, é fruto da reflexão pessoana. Não é Pessoa, surge a partir da coletividade interior pessoana. Até esse ponto da análise, temos duas pessoas envolvidas na criação deste poema: Pessoa e Campos. Para além destes dois eus envolvidos no poema - que já revelam o simpoetar romântico - Caeiro aparece também no poema: Mestre Caeiro, voltei à tua casa do monte. A relação com o Mestre Caeiro é a condição de liberdade do eu lírico. É a partir da visita à casa do monte de Caeiro, que o eu lírico se liberta. Essa experiência de liberdade que ocorre neste poema de Campos se conecta com a leveza da obra de Caeiro, estar livre, sobretudo do pensamento (Pensar é estar doente dos olhos), como escreve Caeiro em sua poesia. Pessoa ao criar seus companheiros de espírito se aproxima da noção de gênio romântico e da simpoesia, onde algumas naturezas que se complementam reciprocamente criam obras em conjunto.

O texto assinado por Reis também revela a questão do gênio romântico, o gênio do gênio que assina a poesia, fruto da multiplicidade pessoana e por outro lado se aproxima da sinfilosofia. Reis se liberta do cristianismo a partir da leitura de $O$ guardador de rebanhos de autoria de Caeiro. Uma obra em conjunto vai se fazendo, a poesia de Caeiro representaria o retorno ao ideal pagão. Reis, Campos e Mora escrevem muitos textos sobre essa questão: a relação entre o Mestre Caeiro e o paganismo. Toda a reflexão sobre o paganismo na obra de Pessoa é elaborada em 
conjunto, duplamente, por um lado, o outro eu pessoano que assina o texto, no caso Reis, já se encontra em diálogo, de alguma forma, com seu criador, Pessoa. Mas para além disto, Pessoa inverte as posições, não é ele o mestre dos seus heterônimos e sim Alberto Caeiro, mestre inclusive do próprio Pessoa. Parece que a obra literária pessoana marca uma nova época nas artes, ele - um homem de gênio - se converteu em toda uma literatura. Uma literatura que dialoga com questões importantes do primeiro romantismo alemão: a questão do gênio, da sinfilosofia e da simpoesia.

\section{Referências Bibliográficas}

NOVALIS. Pólen - Fragmentos, diálogo, monólogo. Tradução, apresentação e notas Rubens Rodrigues Torres Filho. São Paulo: Editora Iluminuras, 2009.

PESSOA, F. Crítica, Ensaio e Entrevistas. Lisboa: Assírio \& Alvim, 1999a.

. Correspondência - 1923-1935. Edição de Manuela Parreira da Silva. Lisboa: Assírio \& Alvim, 1999b.

. Livro do Desasocego. Tomos I e II. Edição de Jerônimo Pizarro. Lisboa INCM, 2010.

REIS, R. Poesia. Edição de Manuela Parreira da Silva. Lisboa: Assírio \& Alvim, 2000.

SCHLEGEL, F. O dialeto dos fragmentos. Tradução, apresentação e notas Márcio Suzuki. São Paulo: Iluminuras, 1997. SOUZA, C.; SUZUKI, M. "Novalis e Pessoa: lucidez poética e reflexão onírica". Revista Filosófica de Coimbra, v. 23, p. 9-26, 2015.

SUZUKI, M. "A ciência simbólica do mundo (Goethe)". In: Adauto Novaes. (Org.). Poetas que pensaram o mundo. São 
Paulo: Companhia das Letras, 2005, v., p. 199-224.

_-_. O gênio romântico - crítica e história na filosofia de Friedrich Schlegel. São Paulo: Iluminuras, 1998. 